\title{
O conflito entre acionistas e gestores e o caso da Petrobrás
}

\author{
Marcelo Sartorio Loural ${ }^{1}$ \\ Vinícius Eduardo Ferrari ${ }^{2}$
}

Resumo: O presente artigo tem por objetivo analisar o caso da Petrobrás no período recente à luz da teoria sobre as disputas entre proprietários e gestores em torno do controle das organizações produtivas de capital aberto. Foram observados nos últimos anos posicionamentos estratégicos distintos por parte da empresa em questão. Até 2013 prevaleceu uma estratégia agressiva de investimentos, que deu lugar à priorização dos retornos de curto prazo a seus acionistas e à venda de ativos fixos (desinvestimento). Dada a importância da Petrobrás para a economia brasileira, o trabalho conclui que tal mudança de estratégia pode ter impactos bastante negativos no longo prazo.

Palavras-chave: Petrobrás; valor ao acionista; investimento.

\begin{abstract}
This paper aims to analyze the case of Petrobras in recent years based on the theory about the conflicts between owners and managers regarding the control of public companies. In recent years there were two different strategic approaches from Petrobras. Until 2013, an aggressive investment strategy prevailed. Since then, several corporative measures giving rise to the prioritization of short-term returns to its shareholders and the sale of fixed assets (divestment). Given the importance of Petrobras to the Brazilian economy, the paper concludes that such a change in strategy can have very negative impacts in the long term.
\end{abstract}

Key-words: Petrobras, shareholder value; investment.

Classificação JEL: G30 - Corporate finance and governance.

\section{Área ABEIN}

Área 3 - Estratégias empresariais, financiamento e governança corporativa

\subsection{Organização empresarial e governança corporativa}

\footnotetext{
${ }^{1}$ Professor do Instituto de Economia e Relações Internacionais da Universidade Federal de Uberlândia.

2 Professor da PUC-Campinas.
} 


\section{O conflito entre acionistas e gestores e o caso da Petrobrás}

\section{Introdução}

O presente artigo tem por objetivo analisar o caso da Petrobrás no período recente à luz da teoria sobre as disputas entre proprietários e gestores em torno do controle das organizações produtivas de capital aberto. Desde sua fundação na década de 1950 a Petrobrás exerce um papel importante na economia brasileira, tanto por se tratar de uma empresa que detém a exploração de um recurso estratégico (petróleo) como por gerar diversos efeitos de encadeamento na estrutura industrial brasileira. Além disso, sendo uma empresa estatal, a Petrobrás exerce outro papel estratégico para a dinâmica da economia brasileira que é a de realizar investimentos à frente da demanda, o chamado investimento autônomo, que tem potencial para dinamizar o crescimento econômico e gerar efeitos multiplicadores.

Foram observados nos últimos anos posicionamentos estratégicos distintos por parte da empresa em questão. Desde meados da década de 2000 até 2013 a Petrobrás adotou um papel ativo na realização e investimentos, em especial após as descobertas do pré-sal, chegando a, em alguns momentos, manter elevado o nível de atividade da economia brasileira ou impedir uma recessão maior, como nos impactos da crise 2008. De 2014 em diante, com denúncias de corrupção envolvendo a empresa e queda nos preços internacionais do petróleo, a estratégia adotada passa a ser muito menos agressiva e seu volume de investimentos cai de maneira significativa, chegando a uma estratégia explícita de desinvestimento.

Neste segundo momento, aparece de maneira clara uma prioridade em mostrar a recuperação da saúde financeira da empresa para que ela apareça como rentável para os acionistas. Dessa forma, analisaremos essa situação a partir da literatura existente sobre os conflitos entre acionistas e gestores, representada pela teoria do shareholder value .

Optamos, assim, por estruturar o artigo em cinco seções além desta introdução, que abarcarão os seguintes temas:

A segunda seção descreverá algumas contribuições de Edith Penrose e John Kenneth Galbraith. Estes autores destacam a influência limitada dos acionistas - durante as décadas de 50 e 60 - no direcionamento dos lucros operacionais gerados pelas corporações produtivas. Neste período, os gestores e proprietários teriam chegado a um consenso em torno do reinvestimento dos lucros no próprio negócio. Ambos os grupos vislumbravam esta estratégia como uma importante premissa para ampliação dos fluxos de rendimentos futuros da empresa.

A terceira seção analisará a desregulamentação financeira vivenciada pela a partir da década de 70. Procuraremos ressaltar os eventos que propiciaram a ocorrência de uma importante mudança na estrutura do mercado acionário: a transferência da posse das carteiras de ações das famílias para os grandes investidores institucionais. Estes acontecimentos estabeleceram as bases para a adoção do shareholder value ${ }^{3}$, um modelo de governança corporativa pautado na busca incessante pela valorização dos

\footnotetext{
${ }^{3}$ Ao longo deste artigo denominaremos as prescrições teóricas que defendem a maximização do retorno das ações corporativas no curto prazo e também as práticas gerenciais destinadas a materializar este objetivo de "shareholder value".
} 
preços das ações mediante crescentes transferências dos lucros corporativos para os acionistas.

A quarta seção descreverá, a partir dos relatórios anuais da administração, as mudanças na estratégia seguida pela Petrobrás no que se refere à explicitação da prioridade aos acionistas minoritários. Na quinta parte serão apresentados dados que reforçam a importância da Petrobrás na economia brasileira e indicam potenciais danos a longo prazo em virtude de se negligenciar tal importância. Por fim, teceremos nossas considerações finais.

\section{A resolução dos conflitos entre proprietários e gestores no pós-Segunda Guerra Mundial.}

Esta seção tem por objetivo resgatar as contribuições de Edith Penrose e John Kenneth Galbraith. Estes autores analisam a atuação das grandes corporações industriais norte-americanas nas décadas imediatamente posteriores à Segunda Guerra Mundial. Estes esforços visam apresentar alguns elementos chaves para a compreensão da resolução dos conflitos entre os acionistas e os gerentes durante a Golden Age.

As obras dos autores mencionados apresentam como ponto de partida comum a questão da separação entre a propriedade e a gestão da empresa diante do surgimento da sociedade anônima de capital aberto:

No passado, a liderança na empresa identificava-se com o empresário. Com o advento da sociedade anônima moderna, o surgimento da organização exigida pela tecnologia e pelo planejamento moderno e a separação entre o dono do capital e o controle da empresa, o empresário não mais existe como pessoa individual na empresa industrial amadurecida. (GALBRAITH, 1983, p. 64)

Galbraith (1983) relata a despersonificação do processo de tomada de decisão vivenciado pelas empresas norte-americanas. O empresário teria sido substituído por uma tecnoestrutura capaz de incorporar todos os indivíduos que trazem conhecimento especializado, talento ou experiência às tomadas de decisão da empresa ${ }^{4}$. Em outros termos, a tecnoestrutura consiste num aparelho relativamente autônomo habilitado para reunir e verificar as informações fornecidas por muitos indivíduos que visa gerenciar decisões complexas que ultrapassam o conhecimento individual dos seus integrantes. Por sua vez, o grau de autonomia da tecnoestrutura estaria diretamente associado à intensidade das intervenções externas dos proprietários na gestão da empresa. $\mathrm{O}$ autor ressalta que o caráter arbitrário de tais pressões externas representa um fator de

\footnotetext{
${ }^{4}$ Tais aspectos também são reconhecidos por Penrose (2006). A autora ressalta que no pós-Segunda Guerra, a gestão das grandes corporações foi transferida dos proprietários para a firma gerencial, aqui subentendida como uma organização comandada por uma administração profissional assalariada comprometida com os interesses de longo prazo das firmas.
} 
distúrbio sobre os mecanismos coletivos de tomada de decisão da estrutura tecnocrática. Estes distúrbios tenderiam a impactar negativamente o desempenho das corporações industriais.

Neste sentido, Galbraith (1983) ressalta que sociedade anônima se ajusta perfeitamente às necessidades da tecnoestrutura ao blindá-la contra as intervenções externas dos acionistas. Ainda segundo o autor estudado, o porte da empresa, a passagem do tempo e a dispersão da propriedade de ações não retiram o direito de voto do acionista, ele pode votar, mas seu voto quando a favor da administração é desnecessário, e, quando contra, infrutífero. Desse modo, o formato jurídico da grande empresa de capital aberto retira o poder de decisão dos indivíduos externos e o realoca internamente junto à tecnoestrutura.

Em síntese, para Galbraith (1983), a autonomia da tecnoestrutura frente às intervenções externas dos acionistas teria proporcionado às condições organizacionais e financeiras capazes de garantir a adaptação da grande empresa moderna frente aos requisitos de tecnologia avançada, grandes quantidades de capital e de amplo planejamento requeridos para o desenvolvimento industrial. Quais então seriam estas condições supridas pela tecnoestrutura?

Um primeiro aspecto apontado por Galbraith (1983) diz respeito à superioridade da tecnoestrutura no processamento de conhecimentos e informações. Convém ressaltar que os processos produtivos modernos exigem a reunião de diversos talentos especializados. Esta necessidade se desdobra em três pontos fundamentais: i) a própria exigência tecnológica da indústria moderna, ou seja, ter homens devidamente qualificados ou dotados de experiência em cada área de conhecimento especializado; ii) a necessidade de reação e previsão decorrente do emprego de tecnologia avançada, do uso associado de capital e da necessidade resultante do planejamento; iii) a necessidade de coordenação destes talentos especializados. Segundo o autor estudado, a incidência destes elementos reforça a necessidade de mecanismos decisórios coletivos. Num ambiente onde as decisões necessitam combinar conhecimentos pertencentes a diversas pessoas diferentes, as deliberações tomadas por comitês decisórios tendem a ser mais sólidas e coerentes que as resoluções tomadas por um único indivíduo.

Por último, e este é o ponto que mais nos interessa, Galbraith (1983) ressalta a capacidade de geração interna de recursos através dos lucros retidos manifestada pela grande corporação de capital aberto norte-americana. Residiria nesta capacidade, o principal fator responsável pela autonomia da tecnoestrutura frente aos acionistas e também a principal fonte de financiamento à expansão industrial.

Existem importantes pontos de convergência entre as informações apresentadas no último parágrafo e as proposições de Edith Penrose. Em Penrose (2006), a autora ressalta que a limitação financeira mais importante ao crescimento das firmas foi removida no pós-Segunda Guerra. As sociedades anônimas foram capazes de eliminar as conexões preexistentes entre a amplitude e a natureza do funcionamento de uma firma e a posição financeira pessoal de seus proprietários. A ampliação da capacidade geração e de retenção dos lucros empresariais teve um papel chave neste processo emancipatório.

$\mathrm{O}$ fortalecimento das fontes internas de financiamento industrial durante as décadas de 50 e 60 está diretamente associado à pulverização da propriedade acionária decorrente da estrutura jurídica da sociedade anônima e à concentração da posse das carteiras de ações nas mãos das famílias norte-americanas. A confluência destes fatores limitou a influência dos acionistas nas votações a respeito do direcionamento dos lucros 
operacionais gerados pelas corporações produtivas. Em contrapartida, os corpos burocráticos profissionais gozaram de ampla autonomia na alocação de tais recursos gerados internamente.

Conforme ressalta Penrose (2006), durante décadas de 60 e 70 os administradores eram amplamente favoráveis à retenção e ao reinvestimento dos lucros na própria firma. A autora argumenta que ao crescimento bem-sucedido das firmas tenderia a ampliar o prestígio, a satisfação pessoal e as remunerações dos seus gestores. Nesta visão, os dividendos são encarados como um custo a ser mantido dentro dos limites mínimos necessários para conservar a felicidade dos investidores, isto é, para atrair o capital adicional necessário, impedir que os acionistas reclamem em grande número e, de maneira geral, manter a reputação de bom investimento da firma.

Não obstante a assimetria de poder no direcionamento dos lucros operacionais, os gestores e os acionistas teriam chegado a um consenso em torno do reinvestimento de tais lucros no próprio negócio. Este consenso perdurou durante as décadas de 50 e 60. Penrose (2006) traz argumentos importantes para inferir a motivação dos administradores e dos proprietários durante a construção do consenso mencionado acima.

Penrose (2006) salienta que o pagamento de dividendos ocasiona a diminuição dos fundos disponíveis para investimentos. Por sua vez, a redução dos investimentos tenderia a comprometer as receitas líquidas futuras da empresa. Ainda segundo a autora, na concepção dos gestores, os benefícios associados ao pagamento corrente de dividendos aos acionistas não compensariam o valor atribuído à perspectiva de maiores ganhos para a empresa no futuro. Diante do conteúdo exposto nesta seção, parece-nos razoável supor que as decisões dos gestores a respeito do reinvestimentos dos resultados operacionais nas firmas refletem, geralmente, um desejo de aumentar lucros totais no longo prazo.

Durante as décadas de 40, 50 e 60 a posse das carteiras de ações estava concentrada nas mãos das famílias norte-americanas. Nesta época, os investimentos das famílias no mercado acionário visavam, sobretudo, a constituição de poupanças de longo prazo destinadas a financiar educação dos filhos, os gastos futuros com saúde associados ao envelhecimento e a suplementar a renda durante o período de aposentadoria. À luz destas motivações de prazo dilato, as famílias teriam se tornado menos reticentes quanto a redução dos dividendos no presente, desde que $o$ reinvestimento destes dividendos nas próprias firmas apresentasse boas perspectivas quanto a ampliação dos lucros empresarias futuros. Deste modo, a retenção dos lucros era concebida como um elemento capaz de fortalecer a riqueza das famílias nos anos vindouros.

\section{A ascensão dos investidores institucionais e o surgimento da doutrina do shareholder value}

Belluzzo (2005) ressalta duas importantes transformações vivenciadas pelo sistema financeiro norte-americano durante os anos 70:

A massa de capital líquido das empresas e a poupança das famílias estão cada vez mais concentradas sob o comando de grandes investidores institucionais. São fundos de pensão, 
fundos mútuos e fundos de hedge que - operando em várias praças financeiras - usam intensamente a técnica de "alavancar" posições em ativos. Simultaneamente, a desregulamentação financeira rompeu os diques impostos - depois da crise dos anos 30 - à ação dos bancos comerciais que voltaram a operar como supermercados financeiros e passaram a se valer da securitização de créditos, o que facilitou o seu envolvimento com o financiamento de posições nos mercados de capitais (BELLUZZO, 2005, p.10).

Esta seção analisará o fortalecimento dos investidores institucionais ${ }^{5}$ De início abordaremos esta questão do ponto de vista teórico. Pretendemos demonstrar como o surgimento e a posterior popularização do conceito de shareholder value forneceu as bases teóricas para a legitimação da crescente participação das instituições financeiras no controle societário e na gestão dos empreendimentos produtivos e comercias. Posteriormente esmiuçaremos as alterações na legislação americana que beneficiaram as instituições de natureza financeira e que viabilizaram as hostile takeover (tomadas de controle hostil) de empreendimentos produtivos e comerciais levadas a cabo pelos investidores institucionais a partir do início da década de 80. Procurar-se-á demonstrar que um dos principais desdobramentos das hostile takeovers consistiu na instauração de modelos de governança empresarial capazes de alinhar a atuação dos gerentes aos interesses dos grandes acionistas.

\subsection{Teoria da Agência e a gestão baseada na maximização do valor do acionista}

A seção anterior ressaltou o consenso (vigente nas décadas de 50 e 60) entre os acionistas e os gestores das grandes corporações industriais em torno do reinvestimento dos lucros operacionais no próprio negócio. A corroboração deste argumento envolveu o resgate da obra de Galbraith (1983). Convém neste momento ressaltar uma advertência emitida pelo economista norte-americano: diante de uma abrupta redução dos lucros corporativos os acionistas poderiam se insurgir contra o corpo burocrático administrativo da empresa. Conforme veremos neste item, este cenário pessimista parece ter se materializado durante as décadas de 70 e 80 .

O início dos anos 70 foi marcado por profundas instabilidades macroeconômicas: a elevação da inflação, a ampliação das incertezas cambiais após derrocada do padrão dólar ouro, a volubilidade crescente das taxas de juros, a dilatação dos déficits orçamentários públicos. A acumulação destes impasses provocou a desaceleração do ritmo de crescimento da demanda agregada. Estes acontecimentos

\footnotetext{
${ }^{5} \mathrm{O}$ escopo desta seção se restringirá aos investidores institucionais. Para uma compreensão mais abrangente a respeito das transformações do sistema financeiro norte-americano durante os anos 70 sugerimos ao leitor a leitura de Braga (1997). Dentre as principais mudanças apontadas pelo autor, convém destacar: "a mudança de natureza do sistema monetário financeiro com o declínio da moeda e dos depósitos bancários enquanto substrato dos financiamentos, substituídos por ativos que geram juros; a securitização que interconecta os mercados creditício e de capitais; a tendência a formação de "conglomerados de serviços financeiros"; [...] a transnacionalização de bancos e empresas; [...] o banco central market oriented (BRAGA, 1997, p.211).
} 
impactaram negativamente as grandes empresas produtivas norte-americanas ${ }^{6}$. Esta tendência à redução da lucratividade foi reforçada pela intensificação da concorrência internacional imposta, sobretudo, pelas empresas japonesas.

Diante deste cenário de erosão da lucratividade e de elevação da capacidade ociosa não planeja o consenso entre proprietários e gestores que perdurou durante as décadas 50 e 60 passou a ser fortemente questionado. Emergiram duros ataques ao corpo gerencial e a própria estrutura da grande corporação produtiva. Dentre estes ataques convém destacar a teoria da agência. Esta teoria enfatiza os conflitos entre os gerentes e os acionistas no tocante a alocação dos recursos corporativos:

Os defensores da teoria da agência argumentavam que, uma vez que os gerentes corporativos não eram disciplinados pelos mecanismos de mercado, eles utilizariam de forma oportunista 0 controle sobre a alocação dos recursos corporativos e sobre os retornos produzidos pela empresa para encher os seus bolsos, ou pelo menos, para perseguir objetivos que eram contrários aos interesses dos acionistas (...) Para os defensores da teoria da agência, a taxa de retorno sobre as ações corporativas representava o índice da performance superior, e a maximização do valor do acionista tornou-se o principal objetivo a ser perseguido (LAZZONICK; O’SULLIVAN, 2000 p. 16)

A teoria da agência, que ganha força nos anos 70 e 80, teria sua origem décadas mais cedo, com a publicação do texto seminal de Berle e Means (1932). Os referidos autores entendem que quando não há separação entre gestão e propriedade a gestão da empresa se pauta pelo entendimento do risco envolvido nos investimentos realizados na firma. Quando ocorre a separação, os gestores nem sempre se pautam dessa maneira, podendo tomar decisões que não visem necessariamente o máximo retorno a quem investiu dinheiro no negócio. Rocha (2009) sintetiza o argumento da seguinte forma:

A transformação da propriedade material em títulos acionários era uma alteração das condições institucionais de funcionamento da economia em relação ao que pressupunha a teoria tradicional. Por exemplo, a motivação do lucro está diretamente ligada com a assunção do risco, portanto, com a propriedade do capital. Por isentar o controlador da riqueza do risco associado à propriedade do capital, não há nada que garanta que estes administradores atuem em benefício dos acionistas, já que os administradores podem ter outros incentivos que não a maximização dos lucros da empresa. Neste contexto, a interpretação da firma como uma instituição voltada à maximização dos lucros torna-se inverossímil nas condições de funcionamento de uma economia

\footnotetext{
${ }^{6}$ Durante o ambiente econômico favorável dos anos 60 estas empresas conduziram amplos investimentos destinados à ampliação da capacidade produtiva. Desta forma, a redução dos níveis de produção nos anos 70 apresentou como contrapartida a elevação da capacidade ociosa. Por consequência, a evolução dos custos fixos unitários exauriu as margens de lucros.
} 
na qual a figura preponderante é a grande sociedade anônima. (ROCHA, 2009: 21).

Assim, a gestão baseada na maximização do valor do acionista somente se viabilizaria mediante a distribuição do fluxo de caixa livre gerado pela empresa:

Uma fraqueza central e uma fonte de desperdícios na corporação de capital aberto é o conflito entre os acionistas e os gerentes sobre o fluxo de caixa livre - isto é, o fluxo de caixa que excede ao necessário para servir de fundo para todos os projetos de investimentos com valores presentes líquidos positivos, quando descontados com relação ao valor relevante do capital. Para uma empresa operar eficazmente e maximizar valores, o fluxo de caixa livre deve ser distribuído aos acionistas e não retidos. Mas isso não acontece frequentemente; a gerência tem poucos incentivos para distribuir os fundos e há somente uns poucos mecanismos para obrigar à distribuição (JENSEN,1989, p. 448).

Os defensores teóricos do shareholder value defendiam a criação de um mercado de controle corporativo destinado a solucionar os conflitos entre acionistas e gerentes. Este mercado disciplinaria os gerentes relutantes em relação à distribuição de recursos aos acionistas ou as companhias que obtivessem desempenhos econômicos pífios. De acordo com este raciocínio, o preço das ações destas companhias cairia e elas seriam adquiridas por outros investidores. Com a mudança de controle societário, os gerentes antigos seriam substituídos por novos gerentes comprometidos com os interesses dos acionistas.

Estes argumentos favoráveis ao estabelecimento de um mercado de controle corporativo também devem ser interpretados como uma ruptura em relação à concepção chandleriana das grandes corporações. Por décadas as firmas foram pensadas como um conjunto coerente de ativos imobilizados destinados à produção. Por sua vez, a emergência do shareholder value consolidou a visão das firmas como um portfólio de ativos. Os acionistas majoritários de uma corporação passaram a vislumbrar as diversas subunidades produtivas de uma empresa como ativos líquidos que poderiam ser expelidos para o mercado de capitais caso ocorresse uma sub-performance. Por outro lado, estes agentes econômicos passaram a interpretar as outras firmas como ativos que poderiam ser incorporados ao seu portfólio, caso esta aquisição ampliasse os rendimentos esperados.

Por último, os defensores do shareholder value ressaltam que quando os empreendimentos corporativos maximizam o valor do acionista, todos os stakeholders trabalhadores, consumidores, fornecedores e distribuidores - obterão um resultado melhor. Deste modo, o desempenho da economia como um todo - não apenas os interesses dos acionistas - seria potencializado (JENSEN, 1989). 


\subsection{As sucessivas desregulamentações vivenciadas pelo sistema financeiro norte- americano nos anos que possibilitaram o fortalecimento dos investidores institucionais}

A cruzada pela implementação do shareholder value nos EUA obteve o suporte de uma crescente fonte de poder econômico - os investidores institucionais. A partir da década de 70 observa-se uma mudança crucial na estrutura do mercado acionário: a transferência da propriedade das carteiras de ações das famílias para instituições de natureza financeira tais como fundos mútuos, fundos de pensão públicos e privados, companhias de seguro.

Conforme ressaltam Lazonick e O’Sullivan (2000, p.23) o percentual das ações corporativas mantidas diretamente por indivíduos caiu de 93\% em 1945 para 42,7\% em 1997. Em contrapartida, os fundos de pensão detinham $24 \%$ do total das ações corporativas americanas em 1997 contra uma participação de meros 0,3\% em 1945. Da mesma forma, a participação dos fundos mútuos evoluiu de 1,5\% em 1945 para 16,2\% em 1997. "Em 1987, a participação dos investidores institucionais no patrimônio líquido das mil maiores corporações norte-americanas era de 46,7\%; em 1995 ela tinha crescido para 57,2\%" (LAZONICK; O'SULLIVAN, 2000). As instituições financeiras claramente se tornaram os acionistas dominantes das grandes corporações dos EUA. Esta mudança na estrutura de propriedade acionária vivenciada pela economia norteamericana propiciou aos acionistas um poder coletivo muito mais forte tanto para influenciar os rendimentos e os preços das ações de sua carteira quanto para impor seus interesses perante os gerentes das corporações. Os próximos parágrafos descrevem as sucessivas flexibilizações regulatórias que possibilitaram estes acontecimentos.

A seção anterior ressaltou as restrições legais quanto à participação dos investidores institucionais no mercado acionário que se estenderam do período posterior a Grande Depressão até o início da década de 70. Este cenário regulatório começou a mudar após o Choque do Petróleo de 1973. Diante da rígida regulação e da aceleração inflacionária, instituições financeiras - tais como bancos e fundos de pensão - se tornaram incapazes de proporcionar retornos positivos aos seus clientes. Os fundos mútuos - investidores em ações e securities - eram contemplados por uma regulação mais branda quanto à alocação do seu portfólio; desta forma, estes fundos tiveram condições de propiciar melhores retornos para o público investidor. Daí decorre a afluência de recursos para estas instituições a partir de 1973. A resposta regulatória ao cenário descrito acima foi o Employee Retirement Income Security Act (1974), que permitiu aos fundos de pensão e às companhias de seguro investir parcelas substanciais do seu portfólio em ações de corporações privadas e outros títulos de risco como junk bonds $^{7}$. Desde então, as famílias dos EUA ampliaram a proporção dos seus ativos financeiros investidos em fundos de pensão e fundos mútuos. $\mathrm{O}$ crescimento da importância destas instituições na administração das poupanças das famílias teve como contrapartida o crescimento da participação de tais instituições financeiras no controle das ações corporativas.

Em 1978 o governo americano decidiu fortalecer o setor bancário na competição travada contra as demais instituições financeiras pela captação de recursos. De início procedeu-se a desregulamentação das taxas de juros que os bancos comerciais e os saving and loans banks (S\&L) poderiam pagar aos depositantes e/ou cobrar aos tomadores de empréstimos. Posteriormente o Garn-St. Germain Act de 1982 estendeu

\footnotetext{
${ }^{7}$ Definição de junk bond: "um título público ou corporativo que as agências de classificação consideram abaixo do nível seguro de investimento" (LAZONICK; O’SULLIVAN, 2000 p. 17).
} 
aos S\&L a permissão para a realização de operações com junk bonds e também autorizou a realização de empréstimos para novos empreendimentos considerados arriscados. Não obstante estas flexibilizações, o governo continuou a garantir os depósitos dos correntistas dos S\&L.

O início dos anos 80 nos EUA foi marcado pelo surgimento de um amplo e dinâmico mercado para títulos below investment grade, os junk bonds. Na década de 70 basicamente os fundos mútuos demandavam estes títulos. As sucessivas desregulamentações financeiras trouxeram inicialmente os fundos de pensão e posteriormente os S\&Ls para participar deste mercado. A partir de então, o mercado acionário norte americano foi sacudido pelas hostile takeover. Nestes movimentos de ataque acionário, os "assaltantes" - normalmente organizações financeiras alinhadas aos interesses dos investidores institucionais - emitiam junk bonds para financiar a tomada do controle acionário de grandes corporações produtivas. Posteriormente, as novas companhias oriundas destas operações herdavam as dívidas emitidas para o financiamento destas fusões.

As hostile takeover se tornaram uma prática financeira padrão em Wall Street durante os anos 80. Em contrapartida, os gerentes das firmas alvos destes ataques ampliaram as recompras - financiadas via emissão de novas dívidas - das ações da própria companhia e/ou as distribuições especiais de dividendos. Estas medidas visavam inflar os preços das ações e dissuadir assaltantes potenciais. Em consequência destas práticas, o endividamento empresarial atingiu recordes históricos. "Somente no período 1984-89, as empresas produtivas contraíram empréstimos de um trilhão de dólares para financiar aquisições corporativas ou para se defender contra estas aquisições" (CROTTY, 2002, p.21).

Os defensores do sharholder value vislumbraram nas aquisições hostis a materialização de um antigo sonho - a instauração de um mercado de controle corporativo. Estes teóricos também aplaudiram o crescimento do endividamento empresarial. Nesta visão, "o endividamento é crucial para a disciplina da gerência e para resolver o conflito do fluxo de caixa livre" (JENSEN,1989, p.462). De acordo com este raciocínio, as despesas com juros forçam os gerentes a liberar recursos que de outra forma eles teriam retido e/ou gastado em projetos de retorno nulo. Ademais, o endividamento impõe a reestruturação da empresa mediante a venda de subunidades deficitárias e também potencializa a busca da eficiência produtiva mediante a redução de custos. Os ganhos oriundos destas operações "podem então ser usados para a redução da dívida a níveis mais sustentáveis, criando uma organização mais enxuta, mais eficiente e mais competitiva" (JENSEN, 1989, p.451).

Constitui-se necessário destacar o impacto das hostile takeover na resolução dos conflitos entres proprietários e gestores. As novas companhias oriundas dos processos de aquisição hostil adotaram estruturas gerenciais alinhadas com os interesses dos investidores institucionais ${ }^{8}$. Deste modo, estas instituições financeiras utilizaram seu

\footnotetext{
8 “Uma Associação LBO (leveraged buyout - compra alavancada) típica consiste em três partes constituintes: uma parceira LBO, que promova transações de fechamento de capitais das empresas e assessore e monitore a gerência em um decorrente relacionamento corporativo (...); gerentes de empresa (...) que permaneçam no empreendimento após a compra; investidores institucionais (...) que proverão fundos às parcerias limitadas que comprarem os direitos acionários e que emprestem dinheiro (junto com os bancos) para financiarem as transações" (JENSEN, 1989, p.453).
}

“A maioria dos fundos usados para absorções são organizados como parcerias limitadas nas quais os parceiros da firma LBO que o patrocina servem como parceiros gerais. O fundo para a compra absorve a 
poderio para alterar a estrutura de remuneração dos top manangers de forma a alinhá-la com os seus interesses. Com a ampliação/generalização do pagamento por opções de ações, a fração da remuneração dos gerentes atrelada ao desempenho do mercado acionário tornou-se preponderante enquanto que a fração relacionada ao desempenho de longo prazo da firma ficou cada vez menor:

Os incentivos para os gerentes fazerem praticamente tudo para ampliarem os preços das ações são enormes. E os incentivos não são para aumentar os lucros e preços compartilhados por uma ou duas décadas, mas para aumentar os lucros - independentemente se eles tiverem que ser reajustados no futuro - por tempo suficiente para os executivos sacarem (CROTTY, 2002, p.2627).

Em síntese, as instituições financeiras claramente se tornaram os acionistas dominantes das grandes corporações dos EUA. Neste contexto, a generalização, ou mesmo a ameaça, das tomadas de controle hostis, fez com que os conflitos entre proprietários e gestores pendessem para o lado dos grandes acionistas. Desse modo, a administração, a remuneração dos gerentes e as estruturas financeiras das empresas foram realinhados de acordo com os interesses dos investidores institucionais. Estes interesses estão corporificados nas estratégias de governança corporativa defendidas pela teoria do shareholder value, tais como a busca incessante pela elevação do preço das ações; a transferência crescente das receitas corporativas para os investidores mediante distribuições de dividendos e programas de recompra de ações; a venda de subunidades produtivas deficitárias.

\section{A situação da Petrobrás em meio aos conflitos entre acionistas e gestores}

A empresa Petróleo Brasileiro S.A. (Petrobrás) é dominante nas atividades de extração, produção e refino de petróleo no Brasil desde sua fundação em 1953, durante do governo de Getúlio Vargas. A empresa deteve o monopólio da exploração do petróleo no Brasil até 1997 e, mesmo depois da quebra deste, ainda responde pela quase totalidade das atividades relacionadas a esse recurso no país.

Quanto à sua estrutura de propriedade, a Petrobrás é considerada uma sociedade de economia mista, sendo 50,3\% de suas ações ordinárias, correspondentes ao capital votante, de propriedade da União (Petrobrás, 2014). As demais ações com direito a voto são distribuídas entre o Banco Nacional de Desenvolvimento Econômico e Social

maior parte dos direitos acionários e às vezes fornece financiamento para o endividamento. $\mathrm{O}$ limitado acordo de parceria nega ao parceiro geral o direito de transferir dinheiro ou outros recursos de uma divisão LBO para outra. Isto é, todos os lucros de um negócio devem ser distribuídos pelos parceiros e outros detentores de direitos sobre aquele negócio (...). Com efeito, a LBO patrocinadora deve pedir permissão a seus investidores institucionais para reinvestir fundos “(JENSEN,1989, p.457-458). 
(BNDES), BNDES participações (BNDESpar), PREVI (fundo de pensão dos funcionários do Banco do Brasil) e outras pessoas físicas e jurídicas residentes no Brasil e no exterior. As ações preferenciais, que não conferem a seus proprietários o direito a voto, também têm sua propriedade dividida entre esses agentes, porém com uma menor participação da União.

Por ter parte de suas ações negociadas em bolsas de valores, a Petrobrás é uma empresa na qual o conflito agente-principal se mostra presente, porém com algumas particularidades. A primeira delas consiste no fato de que o Estado é o acionista majoritário e controlador da empresa, sendo as estratégias por ela adotadas e a indicação do gestor (presidente) definidas pelo governo, ainda que necessite passar pela aprovação do Conselho de Administração. Esse fato leva à segunda particularidade, que reside no papel estratégico da Petrobrás na economia brasileira, que pode pautar as decisões pelo gestor.

O papel estratégico da Petrobrás se revela, essencialmente, em quatro pontos. $\mathrm{O}$ primeiro deles seria a importância do petróleo como fonte energética e insumo para os demais setores da economia. $\mathrm{O}$ segundo corresponde à capacidade da empresa em definir sua política de preços, dado seu caráter quase monopolista, levando em conta a importância de seu produto para as demais atividades econômicas. $\mathrm{O}$ terceiro ponto se refere ao potencial de encadeamentos gerados em atividades auxiliares à exploração do petróleo. Por fim, a Petrobrás é capaz de iniciar um ciclo expansivo de investimentos na economia brasileira de forma autônoma, ou seja, de realizar inversões à frente da demanda e potencializar seu potencial de encadeamento.

Uma maneira de se compreender as estratégias adotadas por uma empresa de capital aberto é através da consulta ao relatório anual da administração desta empresa, publicação destinada a informar aos acionistas sobre as ações tomadas, resultados obtidos e perspectivas futuras. Em consulta aos relatórios anuais da Petrobrás nos últimos 10 anos é possível identificar uma clara mudança de posicionamento da administração da empresa após 2013.

Em 2008, mesmo em meio a um período de turbulência na economia mundial, a Petrobrás prosseguiu com seus projetos de investimento na exploração do petróleo do pré-sal como também na estratégia de fortalecer sua integração em todas as etapas da cadeia produtiva. Conforme nota do então presidente José Sérgio Gabrielli no relatório:

A crise econômica internacional, que acarretou escassez de crédito e forte instabilidade nas cotações do petróleo no segundo semestre, não afetou nosso potencial de investimento. Expandimos os recursos previstos no novo Plano de Negócios, mantendo metas agressivas. (Petrobrás, 2008: 6)

A manutenção de uma estrutura integrada faz parte da estratégia de longo prazo da Petrobras. Por isso, investimos em todos os segmentos da cadeia de petróleo e gás para valorizar nossa produção. A área de Abastecimento recebeu 22,5\% dos investimentos, destinados basicamente à adaptação de unidades de refino para processamento do óleo pesado nacional, aos programas de qualidade dos derivados e à ampliação da capacidade de refino. A companhia também consolidou sua 
presença na área petroquímica - segmento estratégico para diversificar a oferta de produtos - por meio de novas incorporações. (Petrobrás, 2008: 7)

Nota-se a clara manutenção da estratégia de expansão da empresa e da ampliação de sua integração vertical, com a permanência de uma visão de longo prazo, mesmo em um período de crise internacional. Não fosse uma empresa de controle estatal e praticamente monopolista em território brasileiro, tal estratégia dificilmente seria mantida.

O ano de 2014 é essencial para o entendimento da mudança de direcionamento estratégico da Petrobrás. No referido ano os preços internacionais do petróleo caem da faixa de US\$100,00 o barril para cerca de US\$ 30,00, o que impactou fortemente de maneira negativa no caixa da empresa, que veio a apresentar prejuízo. Soma-se a este fator o montante de dívidas assumidas enquanto os preços internacionais estiveram elevados e as descobertas de esquemas de corrupção dentro da empresa no âmbito da operação Lava-Jato para que ocorresse uma forte pressão em direção à adoção de políticas voltadas aos interesses de curto-prazo dos acionistas minoritários. Segundo expresso na mensagem do então presidente Aldemir Bedine:

Adicionalmente, mudanças no contexto dos negócios da Petrobras, em função do declínio dos preços do petróleo, apreciação do dólar e necessidade de reduzir o nível de endividamento, estimularam uma revisão das perspectivas futuras da Companhia e, consequentemente, levaram à necessidade de redução no ritmo de nossos investimentos.

\section{(...)}

Estamos revendo nossos investimentos com o objetivo de priorizar a área de exploração e produção de petróleo e gás, nosso segmento mais rentável. Almejamos construir um plano sustentável sob a ótica do fluxo de caixa, levando em consideração os potenciais impactos na cadeia de suprimentos e, por conseguinte, na nossa curva de produção.

Gostaria de finalizar esta mensagem enfatizando minha convicção de que a Petrobras é e se manterá uma Companhia rentável e eficiente, com significativos aprimoramentos em sua governança corporativa e cada vez mais centrada em retornos para seus acionistas e investidores. (Petrobrás, 2014: 3).

Nos trechos selecionados aparece uma clara mudança de estratégia, com o foco na área de exploração e produção em detrimento da busca por aprimoramento da integração vertical que marcou os anos anteriores. Destaca-se também a mensagem direcionada aos acionistas e investidores de que seus retornos serão prioridade na gestão da companhia.

Em 2016, já na gestão Pedro Parente, a estratégia de desinvestimentos e o foco no retorno de curto-prazo ao acionista são ainda mais evidentes: 
Os quatro outros pilares se integram para permitir a redução do nosso endividamento: (1) uma nova política de preços para a gasolina e o diesel, baseada na paridade internacional e com a definição de que, em nenhum momento estaremos praticando preços abaixo da paridade internacional; (2) maior eficiência em nossos investimentos, traduzindo-se em redução de nossos investimentos com aumento de nossa produção; (3) redução de nossos custos, também sem qualquer prejuízo à nossa segurança e aos nossos objetivos de produção; e (4) realização de parcerias e desinvestimentos com transações que totalizem US\$ 21 bilhões no biênio 2017/18. (Petrobrás, 2016: 8)

Uma mensagem especial dirijo aos nossos acionistas. Os resultados da empresa em 2016 infelizmente não nos permitiram pagar dividendos como gostaríamos. Mas, no conceito de retorno total para o acionista, que inclui a variação do valor de nossas ações no mercado, fomos a empresa que maior retorno apresentou em 2016 no setor de óleo e gás. (Petrobrás, 2016: 9)

No relatório referente ao ano de 2017 destaca-se uma menção à política de preços adotada pela gestão Parente, que se contrapõe em especial à política de evitar reajustes mesmo com os preços internacionais do petróleo em alta adotada entre $2011 \mathrm{e}$ 2014:

Aumentamos a periodicidade no ajuste de preços de diesel e gasolina para torná-la mais aderente ao mercado e suavizamos os reajustes do GLP residencial - sem perda de rentabilidade para a nossa empresa - atendendo às necessidades de nossos consumidores. São certamente lições importantes para uma empresa que por décadas foi monopolista: operar em ambiente concorrencial e pensar em seus clientes. (Petrobrás, 2017: 6).

A mencionada estratégia de desinvestimentos da Petrobrás encontra respaldo na doutrina do shareholder value por ao menos duas razões. A primeira vem da ideia de se ter empresas mais enxutas e que tragam retornos a curto prazo. A própria venda de ativo infla os resultados imediatos de entrada de caixa e parte desse caixa gerado é também transferido aos financistas credores da empresa. A segunda razão pode ser encontrada na abordagem de Fama e Barros (2000) sobre o $q$ de Tobin. O $q$ pode ser definido como a razão entre o valor de mercado de uma empresa e o valor de reposição de seus ativos físicos. Segundos os autores citados, devem ocorrer novos investimentos até o ponto em que o $q$ é maior que $1 \mathrm{e}$, quando o índice for menos que 1 , é recomendado que a empresa venda seus ativos para maximizar o retorno ao acionista. Esse caso ilustra precisamente a situação da Petrobrás com a desvalorização de suas ações ocorrida a partir de 2014.

Percebe-se que nos últimos anos a Petrobrás passou a relegar a segundo plano seu papel estratégico na economia brasileira e, por diversas razões já explicitadas, 
priorizar os retornos aos acionistas. Alguns dos impactos de tais decisões são discutidos na sequência.

\section{A importância da Petrobrás nos investimentos e encadeamentos industriais e os efeitos da mudança de postura da empresa}

Autores como Crotty (2002) e Lazonick e O'Sullivan (2000) já destacaram que a doutrina do shareholder value exerceu impactos negativos relevantes sobre a economia norte-americana desde os anos 1980. De acordo com Lazzonick e O’Sullivan (2000), com o advento do shareholder value, os altos executivos procuraram tornar a empresas sob seu controle mais enxutas, concedendo ênfase especial à redução da força de trabalho empregada na produção. A eliminação dos postos de trabalho ao lado da redução dos salários dos blue-collar workers era vislumbrada como uma estratégia chave na tentativa de ampliar o retorno sobre o patrimônio líquido.

Crotty (2002) aponta o crescimento do annual stock turnorver (a razão entre o valor obtido nas vendas de ações e o valor de mercado das ações) decorrente da ampliação da participação dos investidores institucionais no mercado acionário. Este índice excedeu $100 \%$ na primeira metade de 2002, o que significa que "em média, as ações são mantidas por apenas um ano. Desta forma, acionistas racionais não teriam razões para se preocupar com o desempenho de suas companhias além do horizonte de um ano" (CROTTY, 2002: 23). Esta imposição do horizonte de curto prazo dos investidores institucionais à gestão do setor produtivo teria gerado diversas dificuldades paras as empresas. Um primeiro ponto estaria relacionado aos crescentes problemas de coordenação dos novos investimentos produtivos ocasionados pela incompatibilidade dos prazos dilatados de maturação destes investimentos em relação ao horizonte de ação dos acionistas. Um segundo aspecto ainda mais delicado diz respeito à exigência por resultados imediatos. As pressões do mercado financeiro teriam ocasionado $o$ desmembramento de unidades que falharam em atender as expectativas dos investidores em apenas um ou dois anos.

No caso brasileiro da Petrobrás a conclusão não é diferente. Como destacado acima, o papel estratégico da empresa na economia brasileira vai além da sua política de preços e da importância do petróleo. A Petrobrás tem um grande potencial de investimento autônomo e de geração de encadeamentos intersetoriais.

Com relação aos investimentos, os gráficos 1 e 2 abaixo dão a dimensão de tal importância. No Gráfico 1 é apresentada a taxa de investimento, medida aqui pela razão entre os gastos com aquisição de ativo imobilizado e o Valor da Transformação Industrial (VTI) ${ }^{9}$, para o setor de refino de petróleo e para a média dos demais setores da indústria brasileira. Nota-se que enquanto nos demais setores industriais $o$ investimento não representa mais que $14 \%$ de seu valor adicionado, no setor de petróleo (do qual a Petrobrás representa quase a totalidade) chegou a apresentar picos de $40 \%$, caindo para a faixa dos 30\% em 2014 e 2015 e ainda assim situando-se muito acima dos demais. Cabe ressaltar que o setor de petróleo representa cerca de $15 \%$ do VTI da indústria brasileira, de acordo com a Pesquisa Industrial Anual (PIA/IBGE).

\footnotetext{
${ }^{9}$ Entende-se aqui este indicador como uma proxy setorial da taxa de investimento.
} 
Gráfico 1 - Taxa de investimento - refino de petróleo e demais setores da indústria brasileira, 2007 a 2015.

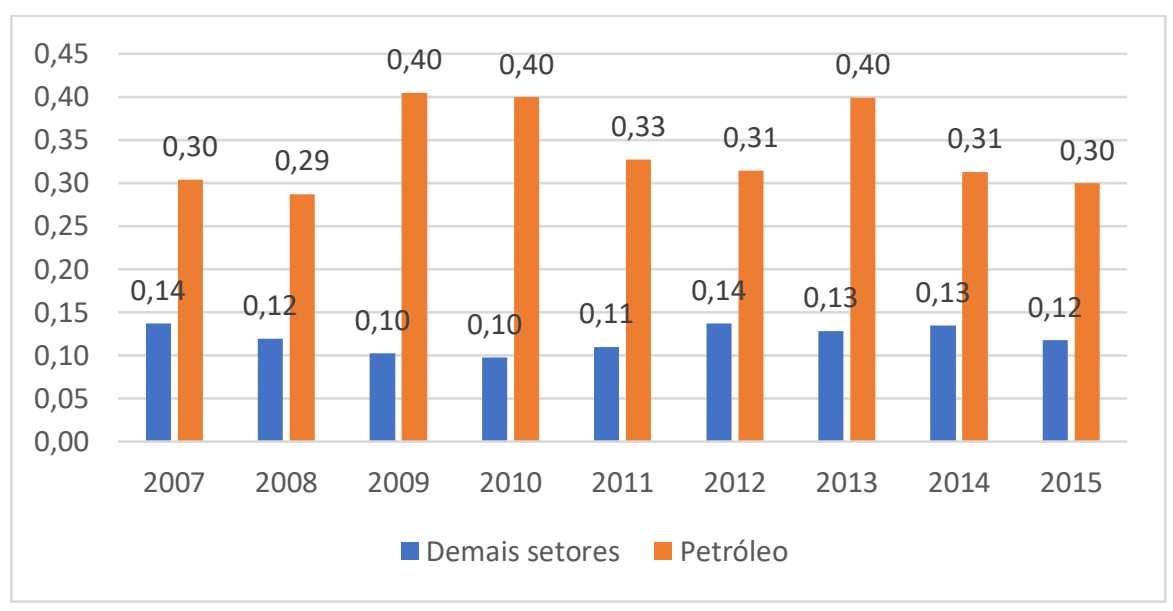

Fonte: Elaboração própria a partir da PIA/IBGE

Os dados expressos no Gráfico 2 complementam a análise iniciada acima. Em especial nos anos de 2009, 2010, 2013 e 2015 o volume de gastos com aquisição de ativo imobilizado do setor de petróleo se aproximou da soma de todos os outros setores da indústria brasileira, reiterando a importância da Petrobrás com seu potencial de investimento autônomo. Destaca-se que 2009 foi o ano de maior impacto da crise internacional sobre o Brasil e tal fato não alterou, naquele momento, a estratégia de expansão dos investimentos da empresa.

\section{Gráfico 2 - Volume de gastos com aquisição de ativo imobilizado (R\$}

bilhões de 2015) - refino de petróleo e demais setores da indústria brasileira, 2007 a 2015.

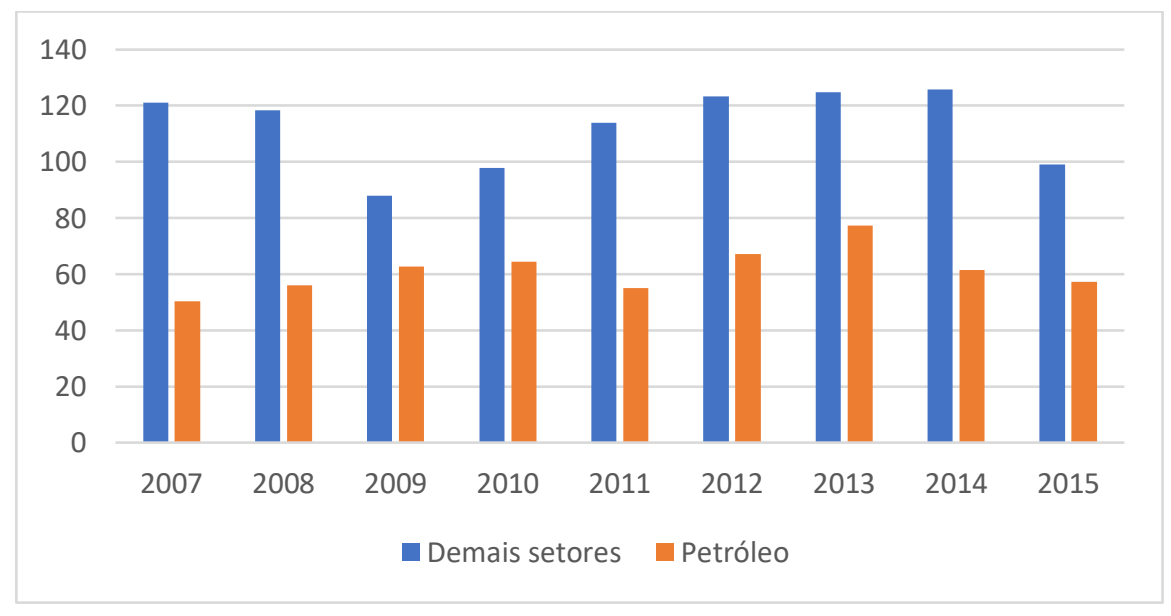

Fonte: Elaboração própria a partir da PIA/IBGE 


\section{Gráfico 3 - Aquisição líquida de imobilizado e Imobilização da receita}

\section{líquida - Petrobrás, 2007 a 2017.}

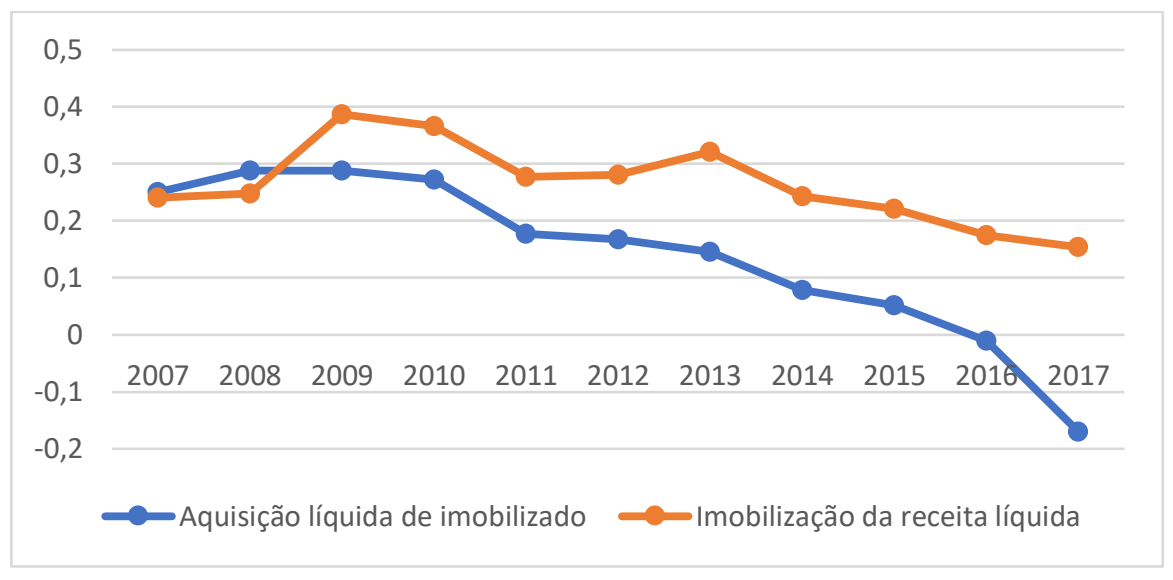

Fonte: Elaboração própria a partir da Economática

No Gráfico 3 é possível identificar a clara mudança de postura da Petrobrás com relação à sua política de investimentos. $\mathrm{O}$ indicador de imobilização da receita líquida indica a parcela das receitas da empresa que é destinada a aquisição de ativo imobilizado. Após atingir $40 \%$ em 2009, este valor apresenta quedas em todos os anos a partir de 2013, chegando a $15 \%$ em 2017. O outro indicador mostrado no gráfico é a aquisição líquida de ativo imobilizado ${ }^{10}$. Se em 2009 e 2010 a Petrobrás adicionou 30\% ao seu estoque de ativo imobilizado, esse valor decresce de maneira vertiginosa após 2013, chegando a patamares negativos em 2016 e 2017, este último mostrando uma perda líquida de $17 \%$ do total de seu imobilizado. Esse dado corrobora a estratégia de desinvestimento mencionada nos últimos relatórios anuais da companhia.

Quanto ao seu potencial de encadeamento, o Gráfico 4 mostra o volume de emprego formal nas atividades auxiliares à exploração de petróleo, a saber: fabricação de máquinas e equipamentos para a prospecção e extração de petróleo; atividades de apoio à extração de petróleo e gás natural; construção de embarcações e estruturas flutuantes. Entende-se que estas sejam as atividades afetadas diretamente pela atividade da Petrobrás. Percebe-se uma significativa recuperação do emprego nestas atividades a partir de 2010, em virtude da continuidade dos investimentos realizados pela estatal petroleira. Tal movimento perdurou até 2013, mantendo-se o nível de emprego em 2014 e a partir de então iniciando-se uma queda vertiginosa dos postos de trabalho formais, com uma perda de 30 mil empregos em dois anos.

\footnotetext{
${ }^{10}$ Aquisição líquida de imobilizado: constrói-se este indicador a partir de informações do Demonstrativo de Fluxo de Caixa e do ativo. No numerador contabilizam-se os gastos com aquisição e ativos fixos e diferido subtraindo a depreciação e as vendas de ativos fixos. No denominador é colocado o estoque de imobilizado e diferido da empresa. O indicador mostra, portanto, a porcentagem do ativo imobilizado que foi efetivamente adicionada ao estoque no ano, já descontando eventuais vendas e a reposição da depreciação. Assim, é possível se ter uma ideia dos investimentos que realmente adicionaram capacidade de produção e de geração de empregos e daqueles que se referem apenas à modernização da capacidade existente.
} 


\section{Gráfico 4 - Emprego formal na indústria parapetroleira - 2007 a 2016.}

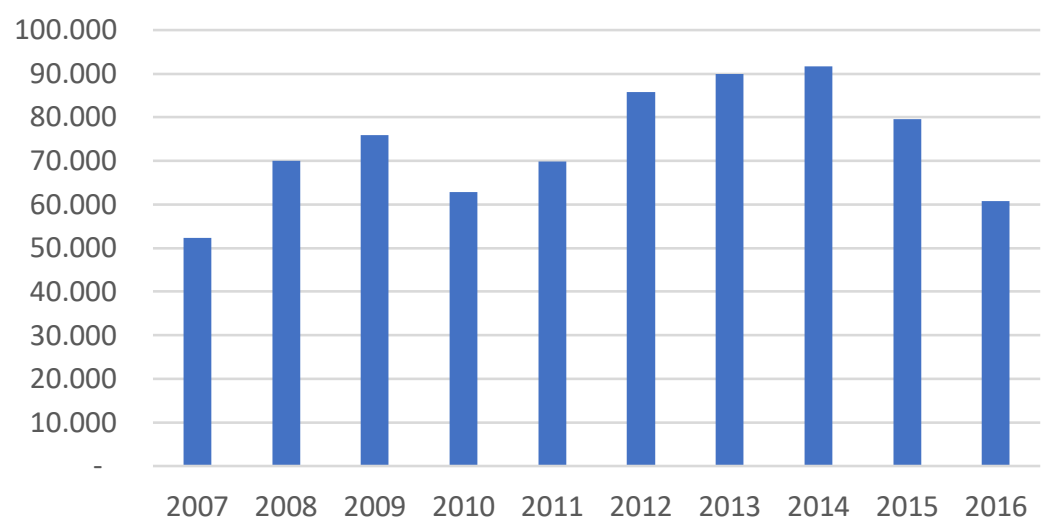

Fonte: Elaboração própria a partir da RAIS/MTE

Entende-se, portanto, a importância da Petrobrás nos investimentos realizados pela indústria brasileira e seus impactos sobre o nível de atividade da economia como um todo, dada a relevância do setor e da empresa, e da capacidade de gerar dinamismo em atividades auxiliares à extração do petróleo. A mudança de postura adotada a partir de 2014 e com mais força após 2015 é evidenciada pelos dados referentes à aquisição de ativo imobilizado e traz reflexos importantes sobre a economia brasileira.

\section{Considerações finais}

Segundo o pensamento pós-keynesiano, a variável macroeconômica investimento exerce um papel determinante sobre a evolução da demanda agregada e sobre o nível de emprego. De acordo com esta visão, a prosperidade econômica da Golden Age se materializou devido ao crescimento vigoroso dos investimentos industriais possibilitado. Nesse cenário, houve a construção de um consenso entre proprietários e gestores em torno do reinvestimento dos lucros operacionais na própria empresa, com a ideia de que gerariam um maior retorno no longo prazo. Mesmos e tratando de épocas distintas, pode-se dizer que as estratégias de investimento da Petrobrás até 2013 partiam deste perfil.

A redução dos investimentos produtivos decorrente das práticas gerencias associadas ao shareholder value exerce forte impacto negativo sobre a evolução da renda agregada, do produto industrial e do emprego. Tal argumento, defendido por autores como Lazonick \& O'Sullivan e Crotty, é também aplicável ao caso brasileiro da Petrobrás.

Explicitada a relevância da Petrobrás nos investimentos realizados no Brasil, em especial após a crise de 2008, percebe-se reorientação da empresa em direção à diminuição de suas inversões ou até mesmo desinvestimento. Em se mantendo esse comportamento, são baixas as perspectivas de retomada do investimento na economia brasileira, dada a alta participação da Petrobrás, os encadeamentos por ela gerados e o caráter autônomo de seus investimentos, que possibilita a dinamização de uma fase ascendente do ciclo econômico. Sem o investimento autônomo de uma empresa como a 
Petrobrás, não se enxergam perspectivas para a retomada investimento induzido pela demanda neste momento de baixa atividade econômica.

Certamente existiram razões que justificam, em parte, essa mudança de comportamento da empresa, como seu nível de endividamento, as mudanças nos preços internacionais do petróleo e as investigações de corrupção dentro da companhia. Contudo, dado o papel estratégico da empresa, deve-se preservar sua estrutura e seu patrimônio e seu potencial dinamizador da economia brasileira. Sendo assim, seu caráter como empresa pública não deve ser relegado a segundo plano.

\section{Referências bibliográficas}

BELLUZZO, L.G. Prefácio. In:__ CHESNAIS, F. A Finança Mundializada. São Paulo: Bom tempo, 2005.

BERLE, A. \& MEANS, G. (1932). A moderna sociedade anônima e a propriedade privada. São Paulo: Abril Cultural, 1984. (Os economistas).

BRAGA, J.C.S. Financerização Global: o padrão sistêmico de riqueza do capitalismo contemporâneo. In: Fiori, J. L; Tavares, M. C. (orgs) Poder e Dinheiro uma economia política da globalização. Petrópolis: Editora Vozes, p.195-242, 1997.

CROTTY, J. The Effects of Increased Product MarketCompetition and Changes in Financial Markets on the Performance of Nonfinancial Corporations in the Neoliberal Era. Working Paper Series University of Massachusetts. Amherst, n.44, p. 1-41, 2002.

ECONOMÁTICA. Base de dados. Vários anos.

FAMA, R. \& BARROS, L. Q de Tobin e seu uso em finanças: aspectos metodológicos e conceituais. In: Cadernos de Pesquisa em Administração v. 7, no. 4. São Paulo, 2000.

GALBRAITH, J.K. O novo estado industrial. $3^{\text {a. }}$ edição. São Paulo: Nova Cultural, 1983.

HOBSON, J. A Evolução do Capitalismo Moderno. São Paulo: Abril S.A., 1983.

JENSEN, M.C. O Eclipse da Corporação de Capital Aberto. In: Montgomery, A.C; Porter, M.E. (orgs) Estratégia: a busca da vantagem competitiva. Rio de Janeiro: Campus, p.441-448, 1989.

LAZONICK, W; O’SULLIVAN, M. Maximizing Shareholder Value: A New Ideology of Corporate Governance. Economy and Society, n.29, vol.1,p.13-35, 2000.

PENROSE, E. A teoria do crescimento da firma. Campinas: Editora Unicamp, 2006.

Pesquisa Industrial Anual (PIA). Instituto Brasileiro de Geografia e Estatística (IBGE). Vários anos.

PETROBRÁS. Relatório anuais. Vários anos. 
RELAÇÃO ANUAL DE INFORMAÇÕES SOCIAIS (RAIS) - Ministério do Trabalho e Emprego - vários anos.

ROCHA, M. A. M. da. Estrutura de capital e sistemas nacionais de governança: um estudo a partir da privatização do setor petroquímico brasileiro. Campinas: Unicamp, 2009 (tese de doutorado).

WOLFE, R.M. Business R\&D Performed in the United States Cost \$291 Billion in 2008 and \$282 Billion in 2009. National Science Foundation, 2012. Disponível no sítio: http://www.nsf.gov/statistics/infbrief/nsf12309/nsf12309.pdf 